\title{
EL CABILDO DE LA \\ CATEDRAL Y \\ LA GUERRA CON \\ ESTADOS UNIDOS*
}

Marta García Ugarte**

\section{Los estudios sobre la participación}

de la jerarquía católica durante la guerra con Estados Unidos son escasos. ${ }^{1}$ Algunas publicaciones, ya clásicas en nuestro medio, ${ }^{2}$ se han referido a las relaciones tormentosas que se establecieron entre los gobiernos y la jerarquía respecto a los préstamos forzosos ${ }^{3}$ y otras, las

* El cabildo de la catedral metropolitana de México durante la guerra con los Estados Unidos (1846-1848) es el título original, abreviado por razones de espacio.

** UNAM, CIESAS, Departamento Académico de Estudios Generales, ITAM.

${ }^{1}$ Entre los trabajos que pueden mencionarse están: Alicia Tecuanhuey Sandoval, en su texto, "Puebla durante la invasión norteamericana", menciona el papel jugado por el cabildo de la catedral de Puebla. Consultarlo en Josefina Zoraida Vázquez, coordinadora, México al tiempo de su guerra con Esados Unidos (1846-1848). César Navarro Gallegos, analiza la participación de la jerarquía y el gobierno duranguense en su artículo "Una santa alianza: el gobierno duranguense y la jerarquía eclesiástica durante la intervención norteamericana", en Laura Herrera Serna, coordinádora, México en guerra (1846-1848), 1997, México, Museo Nacional de las Intervenciones y Consejo Nacional para la Cultura y las Artes.

${ }^{2}$ Jan Bazant, Los bienes de la Iglesia en México: aspectos económicos y sociales de la revolución liberal, 1971, México, El Colegio de México.

${ }^{3}$ Uno de los trabajos recientes sobre el asunto de las finanzas de la guerra es el artículo de Carlos Rodríguez Venegas, "Las finarizas públicas y la guerra con Estados Unidos, 1846-1848”, en Josefina Vázquez, op.cit. 
MARTA GARCÍA UGARTE

menos, han hecho referencia a la oposición de los obispos a la reforma de 1833. Pese a ello, y al nuevo interés que ha despertado el tema en la actualidad, todavía se desconoce el papel que tuvo el cabildo de la catedral de México durante esos años.

Esa falta de información motivó mi interés en conocer los términos de las negociaciones del cabildo catedralicio de la ciudad de México con el gobierno y la forma como concibieron el conflicto y su colaboración. El trabajo, que es tan sólo un avance de investigación, ${ }^{4}$ parte de una hipótesis general: la jerarquía católica fue sensible a los gobiernos del partido del Orden tanto por las garantías que otorgaba a la Iglesia como porque compartían una misma visión del mundo y de la sociedad mexicana.

\section{Tiempo de guerra (11 de mayo de 1846 a 2 de febrero de 1848)}

El 11 de mayo de 1846, el gobierno de Estados Unidos declaró la guerra a México, dos días después, antes de que México hiciera su declaración formal de guerra, ${ }^{5}$ el Ministro de Justicia y Negocios Eclesiásticos envió una circular al vicario capitular de la arquidiócesis a fin de convocar a una reunión de eclesiásticos ${ }^{6}$ para auxiliar al gobier-

${ }^{4}$ Es preciso señalar que el artículo fue escrito a partir del análisis de la información que contienen la sección de correspondencia y las actas del cabildo de la catedral metropolitana de México. El fondo documental de este archivo, que fue consultado en la copia microfilmada que guarda Condumex, es muy rico. Pero, como se sabe, ningún archivo es suficiente en sí mismo. De acuerdo con esto, algunos procesos podrán encontrar una explicación más acabada con la información que guarda el fondo de Justicia y Negocios Eclesiásticos del Archivo General de la Nación o la propia del Arzobispado, entre otros.

${ }^{5}$ El gobierno mexicano hizo su declaración formal de guerra el 7 de julio de 1846.

${ }^{6}$ Se citaría a los prelados de las corporaciones religiosas, a los mayordomos de exclaustradas, de cofradías y a cuantas personas de uno y otro clero se creyera conveniente. 
EL CABILDO DE LA CATEDRAL

no con un préstamo económico. Con esos recursos se podría combatir al Ejército invasor que, según el plan que se había trazado, tenía la intención de "absorberse toda la República de México". Era preciso que se ayudara al gobierno porque la derrota de México traería males imponderables contra la religión,

introduciéndonos desde luego con la libertad de cultos, los muchos y muy absurdos que ellos profesan, y la consiguiente corrupción de costumbres que más que en otros reina en ellos principalmente por su desenfrenada ambición e insaciable ansia de dinero. Es bien público que animan a sus soldados con la esperanza de que disfrutarán de los bienes de nuestras corporaciones eclesiásticas y de las alhajas que adornan nuestras Iglesias...los referidos bienes son perdidos si llegáramos a sucumbir con la guerra que tenemos con semejante nación. ${ }^{?}$

Esa idea, de que los norteamericanos veían con ojos de codicia los bienes eclesiásticos mexicanos, que ya había sido expresada en 1837, preocupaba al presidente James Knox Polk porque sabía que el poder de la Iglesia católica en México era enorme. Por esa razón pidió a John Hughes, obispo de Nueva York, que lo ayudara a desvanecer los prejuicios que los sacerdotes católicos en México tenían sobre los Estados Unidos y sobre sus "designios hostiles...respecto a su religión". El presidente Polk explicó al obispo que si el clero creyera esas versiones, harían una desesperada resistencia a nuestro Ejército en la presente guerra. ${ }^{8}$

Según el diario del presidente Polk, el obispo Hughes estuvo de acuerdo en apoyarlo para que sacerdotes que hablaran el español acompañaran al Ejército como capellanes y otros se adelantaran a las fuerzas armadas dando seguridad al clero católico. Mencionó que él conocía

${ }^{7}$ Oficio del Ministro de Justicia y Negocios Eclesiásticos, inserta en el Acta del Cabildo del 13 de mayo de 1846.

${ }^{8}$ Diario del presidente Polk (1845-1849), recopilación, traducción, prólogo y notas de Luis Cabrera, 1948, México, Antigua librería Robredo, V. I, p. 71. 


\section{MARTA GARCÍA UGARTE}

al arzobispo de México y podría, si así lo deseaba su gobierno, acudir a México. ${ }^{9}$ Si la estrategia se llevó a cabo, asunto que hay que indagar en los archivos de Estados Unidos, no produjo el efecto esperado porque el cabildo siempre se mostró temeroso del Ejército norteamericano y de las creencias religiosas de la tropa.

E1 Ministro mexicano no sólo mostraba los riesgos que corrían los bienes eclesiales ante el Ejercito invasor, también refería la amenaza que representaba el partido liberal que había dado muestras de su ideología en su congreso de 1833-1834. Además, el nuevo gobierno había encontrado a la nación en bancarrota. Si bien tenía tropas y reemplazos para atender la guerra, carecía de dinero para alimentarlas, transportarlas y para comprar armas y municiones. Esas condiciones lo obligaban a asignar un préstamo forzoso a la Iglesia metropolitana de $98 \mathrm{mil}$ pesos mensuales. Pero el cabildo respondió que no podía acceder a la solicitud. ${ }^{10}$ Ante la negativa, el presidente de la República, Mariano Salas, convocó a una junta el 14 de agosto en donde el Ministro de Hacienda, Valentín Gómez Farías, hizo una relación de los motivos que tenía el gobierno para pedir un préstamo de $600 \mathrm{mil}$ pesos.

Gómez Farías, quien era poco apreciado por el clero por los acontecimientos del año 33, mostró una vez más su nula capacidad de negociación, su incomprensión de la estructura eclesiástica y su autoritarismo. Desesperado ante la lentitud y la renuencia del cabildo catedralicio, decidió por sí mismo, y como recurso de ley, que la Iglesia metropolitana debería aportar 50 mil pesos mensuales durante seis meses. Si al término de este lapso la guerra continuaba, la autoridad diocesana entregaría otros 60 mil. Quedaba vigente la autorización para vender fincas otorgada al vicario capitular el 29 de junio de 1846 . Se hipotecaban, a

${ }^{9}$ La postura de la jerarquía católica en Estados Unidos con respecto a la guerra es un apartado de la historia que hay que indagar. Sin duda, arrojará nuevas luces a la interpretación de las relaciones internacionales de la Santa Sede y de su influencia en la historia de México en estos años.

${ }^{10}$ Los obispados de Puebla y Michoacán estaban en la misma situación económica que la arquidiócesis. Por eso, los titulares diocesanos se negaron a hacer el préstamo. 
EL CABILDO DE LA CATEDRAL

razón de $5 \%$ anual, los productos del papel sellado para pagar el préstamo, entendiéndose que dichos réditos no empezarían a satisfacerse hasta después de concluida la guerra. Como era de esperarse, los miembros del cabildo se indignaron con esta comunicación de Gómez Farías porque presentaba el asunto como un acuerdo entre las dos potestades, cuando la Iglesia había aceptado dicha aportación de forma violenta y coactiva. ${ }^{11}$

El general Santa Anna llegó a la ciudad de México a principios de julio. De inmediato dijo al Vicario Capitular que necesitaba 20 millones de pesos para financiar la guerra. Mientras los conseguía, era urgente que el cabildo aceptara una hipoteca general de un millón de pesos. El cabildo, que no quería conceder el préstamo para caminar sobre sendero más seguro, revisó el expediente de $1837 .{ }^{12}$ Al igual que en ese año, se dijo que la cantidad por la que se otorgaba la hipoteca la había de recibir el Supremo Gobierno en efectivo y no en 'papeles', para evitar la ganancia de los usureros. Pero no se prestó el millón solicitado sino $600 \mathrm{mil}$ pesos, que había sido el monto asignado por Gómez Farías. Además, los miembros del cabildo decían que debía cesar, desde luego, el préstamo de $50 \mathrm{mil}$ pesos que se entregaba mensualmente y el acuerdo de dar otros 60 mil si continuaba la guerra con Estados Unidos. $^{13}$

Durante esta negociación, Valentín Gómez Farías fue sustituido en el ministerio de hacienda por Antonio Haro y Tamariz, quien era un hombre de bien y de ideas avanzadas pero moderadas. El 30 de septiembre Haro citó al cabildo a una reunión que se verificaría en el salón principal del Palacio Nacional ${ }^{14}$ para discutir el préstamo. En apariencia las negociaciones no tuvieron el resultado que se esperaba

11 Acta del Cabildo del 18 de agosto de 1846.

${ }^{12}$ La reflexión del cabildo de la catedral metropolitana en 1837 para avalar con hipoteca sobre sus bienes un crédito al gobierno es de una belleza y singularidad extraordinaria.

${ }^{13}$ Acta del Cabildo del 23 de septiembre de 1846.

${ }^{14}$ Acta del Cabildo del $1^{\circ}$ de octubre de 1846. 


\section{MARTA GARCIA UGARTE}

porque una semana más tarde, el 8 de octubre, Haro y Tamariz se presentó en la sesión del cabildo para entregarles un proyecto de ley sobre ventas de fincas urbanas de la Iglesia a sus actuales inquilinos, que deseaba fuera revisado por el cabildo antes de su publicación.

El cabildo escribió de inmediato al Presidente para informarle que el proyecto era inadmisible porque atacaba muy directamente la propiedad de la Iglesia y comprometía la conciencia y reputación del Supremo Gobierno. Además de enarbolar las condenas reservadas por el Concilio de Trento y el Provincial mexicano para todos aquellos que atentaban contra los bienes de la Iglesia, los capitulares recordaron que la experiencia en Guadalajara en 1833 había demostrado que la venta de los bienes eclesiásticos sólo era útil para los compradores, mientras que el gobierno obtenía poco beneficio. ${ }^{15}$ José María Durán, el Ministro de Justicia y Negocios Eclesiásticos, no entendía el porqué del pánico de los miembros del Cabildo cuando la medida era benéfica a la Iglesia y evitaría que, con la intervención norteamericana, se perdiera todo. ${ }^{16}$

El decreto establecía que los compradores serían los inquilinos y si tenían varias fincas subarrendadas, podrían escoger. la que deseaban comprar y si arrendaban una sola y la tenían subarrendada ellos ten-

54 drían preferencia de compra. También preveía el procedimiento para las casas de vecindad. Si ninguno de los arrendadores tomaba la providencia, las propiedades serían rematas en almoneda pública. El precio se establecería por la renta o inquilinato, a razón de un cinco por ciento. ${ }^{17} \mathrm{La}$ única ventaja, destacada por los ministros y acremente criticada por el dictamen del cabildo, era que la prevención $4^{\mathrm{a}}$ del Art. 1, establecía que el reconocimiento del precio o del capital de los compradores sería perpetuo, pero podrían redimirlo de acuerdo con los censatarios, previa licencia del gobierno.

\section{${ }^{15}$ Acta del Cabildo del 9 de octubre de 1846.}

${ }^{16}$ Carta del 12 de octubre de 1846, dirigida al Vicario capitular del arzobispado.

${ }^{17}$ La copia del decreto se registró en el Acta del Cabildo del 13 de octubre de 1846. 
Para el cabildo, se trataba de un despojo descarado. En su representación destacó que resultaba incomprensible que el Ministro dijera que la Iglesia obtendría beneficio por la enajenación de sus propiedades.

¿Quién será pues el inventor de esta nueva jurisprudencia, por cuyos principios se intenta persuadir hoy al clero mejicano, que les es ventajoso deshacerse de todas sus propiedades, conservando sólo en ella el derecho de su censo perpetuo, que unos juristas aplican a las servidumbres reales, y otros a la hipoteca? Si tales utilidades resultan de las enajenaciones de los bienes raíces a censo ¿por qué no se da una ley general, que obligue a sus dueños a venderlas todas con esa calidad? ¿Y por qué los propietarios no se apresuran todos a deshacerse de las fincas que les son gravosas, acogiéndose a ese bello ideal del reconocimiento perpetuo?

Se trataba, se aseguraba, de un abuso que violaba la fracción $3^{a}$ del artículo 112 constitucional. ${ }^{18} \mathrm{Se}$ argumentó que existía una gran diferencia entre el dominio y los demás derechos reales de las cosas. ${ }^{19} \mathrm{La}$ oposición del cabildo al decreto fue secundada por los obispos de la República. Pero como el país estaba en guerra y efectivamente el gobierno carecía de recursos, el cabildo de la catedral metropolitana consideró que era preciso proporcionar algún auxilio. Como tampoco se tenía numerario, era necesario aceptar la hipoteca que proponía el gobierno. Con esa reflexión, el cabildo accedió a proporcionar al erario público un millón de pesos, que obtendría del crédito que pediría a los capitalistas nacionales y extranjeros, garantizándolo con sus bienes. Como tuvo problemas para obtener el préstamo, redujo el monto de la hipoteca de un millón a 850 mil pesos. Sólo faltaba establecer los términos del préstamo.

${ }^{18} \mathrm{El}$ artículo establecía que el presidente no podría ocupar la propiedad de ningún particular ni corporación...sin previa autorización del Senado ...indemnizando siempre a la parte interesada.

${ }^{19}$ Acta del Cabildo del 15 de octubre de 1846. 


\section{MARTA GARCÍA UGARTE}

Ante la urgencia de recursos, el Ministro de Hacienda continuamente pedía adelantos de dinero del préstamo que se estaba negociando. ${ }^{20}$ Con esa premisa, el 16 de noviembre se presentó ante el cabildo eclesiástico para informarle que el Ejército invasor, comandado por Zachary Taylor, estaba por romper la tregua pactada en Monterrey. Ante el riesgo que corrían tanto la nación como la Iglesia mexicana si México llegaba a ser territorio americano, las dificultades que se habían presentado para acabar de formalizar el crédito de un millón de pesos deberían ignorarse. De triunfar los invasores, la Iglesia sería considerada una "hermana tolerada de sectas heterodoxas". E1 Ministro aclaró que el presupuesto mensual era de 300 mil pesos sólo en lo interior y el pedido que se había hecho desde Veracruz era de $800 \mathrm{mil}$.

Ante la premura del gobierno, el 19 de noviembre de 1846 se publicó un decreto que aseguraba un crédito de dos millones de pesos con bienes de la Iglesia. ${ }^{21}$ En esta ocasión, el cabildo deliberó que no era conveniente hacer una oposición cerrada a esta decisión, por la guerra que vivía el país. Tampoco podían quedarse callados, por el precedente que establecía. Así, acordaron que la protesta debería efectuarse en los "términos más suaves y prudentes", de manera que se abriera la puerta al Supremo Gobierno para establecer un nuevo arreglo. Que ya se había accedido, bajo ciertas condiciones, al préstamo de un millón de pesos, y a la hipoteca de bienes eclesiásticos para garantizar el préstamo de 850 mil pesos. Por lo mismo era preciso decirle al Ministro de Hacienda que no se aceptaba el decreto del 19 de noviembre pero que el cabildo estaba bien dispuesto a establecer algún otro arreglo 'franco y amistoso'.22

${ }^{20}$ En la sesión del cabildo del 15 de noviembre, el tesorero de la Iglesia informó que el Ministro de Hacienda le había pedido 150 mil pesos de adelanto.

${ }^{21}$ Acta del Cabildo del 25 de noviembre de 1846. Rollo 1239, vol. $n^{\circ} 80$, Exp. 9.

${ }^{22}$ Acta del Cabildo de la catedral metropolitana del 25 de noviembre de 1846. 


\section{EL CABILDO DE LA CATEDRAL}

En esos términos, el cabildo ofreció 850 mil pesos, préstamo que se cubriría entregando 10 mil pesos mensuales. Se trató también la forma de avalar el préstamo de los 20 millones que el gobierno estaba negociando con Inglaterra. Posteriormente, el cabildo, presionado por el Ministro de Hacienda, aceptó aumentar sus entregas mensuales a 20 mil pesos.

Como las cosas se hablaban pero no se,traducían en entregas, el 2 de diciembre el gobierno hizo saber al cabildo que se vencía el plazo establecido en el decreto del 19 de noviembre (que aseguraba un préstamo de dos millones de pesos). Asimismo, que no quería hacer uso de violencia, por lo que esperaría que el clero estuviera dispuesto a la modificación que establecía la entrega de 20 mil pesos mensuales.

En esta ocasión, el gobierno contraía dos préstamos, uno con los prestamistas y otro con el venerable clero. El primer préstamo obligaba al clero a formar un fondo de $850 \mathrm{mil}$ pesos para responder por el que negociaría el gobierno, y que el clero pagaría íntegramente dentro de tres años nueve meses, contados desde el $1^{\circ}$ de diciembre de 1846 . E1 del clero ascendía a 500 mil pesos, que pagaría en abonos mensuales de 14 mil, comenzando a pagarlos el 28 de febrero de 1847 . Bajo esas bases el gobierno acordaría cesar el efecto del decreto del 19 de noviembre. La Iglesia estableció sus exigencias para otorgar el crédito: que en términos de tres años no se le solicitara otra contribución y que se derogara el decreto del 19 de noviembre. ${ }^{23}$

Al empezar el año 1847, ocupando Santa Anna la presidencia y Gómez Farías la vicepresidencia, el cabildo decidió suspender las discusiones internas sobre las asignaciones mensuales que se debian entregar al gobierno, porque se había presentado al congreso un decreto que ordenaba la ocupación de los bienes eclesiásticos. ${ }^{24}$ Tal posibilidad suscitó un fuerte temor en el cabildo. Por esa razón se decidió que sus miembros en general y el Vicario Capitular en particular trataran

${ }^{23}$ En total, durante 1846 la Iglesia había respaldado al gobierno por dos millones 800 mil pesos.

${ }^{24}$ Acta dél Cabildo de la catedral metropolitana del 7 de enero de 1847. 


\section{MARTA GARCÍA UGARTE}

de hablar con los diputados y que se enviara una representación al Supremo Gobierno y al congreso, y también una nota a los estados de México y de Querétaro así como a los obispos de la República, informándoles de la decisión en ciernes.

El 10 de enero de 1847 el congreso aprobó el proyecto de ocupación de bienes eclesiásticos para proporcionarse hasta 15 millones de pesos. De inmediato, el cabildo envió una representación al presidente diciendo que no consentía en manera alguna en las medidas del citado proyecto para no incurrir en las censuras del Santo Concilio de Trento, que fulminaba a quienes apoyaban este tipo de acciones. De ahí que presentaba su más solemne protesta, dado el caso de que llegara a sancionarse. El cabildo decidió enviar un segunda representación para protestar por la medida. Algunos segmentos de ésta son singulares porque refieren la serie de sacrificios que había hecho la Iglesia para auxiliar al gobierno:

Después que la Iglesia mexicana ha tenido abiertas sus arcas para auxiliar a la nación en todas sus necesidades; que desde la independencia a esta fecha ha entregado continua y sucesivamente gruesas sumas: que ha tomado siempre de lo más florido de sus bienes; que jamás en sus prestaciones ha pretendido recompensas; que con la mayor religiosidad ha satisfecho las muchas contribuciones que se le han impuesto, y que ni una sola vez ha sido indiferente a las angustias de erario; en vez de lograr en recompensa de esta conducta la consideración a que era tan acreedora, se ha decretado la ocupación de sus bienes... ${ }^{25}$

Para tratar el asunto que tenía tan movilizada a la Iglesia, el viceprésidente convocó a una junta en la que hizo una larga exposición de la necesidad de recursos que requería para auxiliar al Ejército y salvar la independencia del país. Argumentó que ésa había sido la razón que

${ }^{25}$ Acta de Cabildo de la catedral metropolitana del 11 de enero de 1847. 


\section{EL CABILDO DE LA CATEDRAL}

tenía en mente el congreso al expedir el decreto de ocupación de bienes eclesiásticos. Comentó que tal medida podía evitarse si la Iglesia accedía a dar 500 mil pesos mensuales hasta completar los 15 millones. Además, dijo a los miembros del cabildo que habían asistido a la junta, que "esperaba por parte de las autoridades eclesiásticas se tomaran providencias para que no se predicase en contra del dicho decreto", pues si esto ocurría o se obraba contra la misma ley se dictarían fuertes medidas. ${ }^{26}$ Lejos de lo deseado por el gobierno, cuando los señores capitulares fueron informados de la postura del vicepresidente, decidieron imprimir dos mil ejemplares de la representación que habían preparado para repartirlos por toda la república.

Como el decreto, de manera independiente a la oposición de la Iglesia, se iba a publicar el 13 de enero, se tomó la decisión de clausurar la iglesia. Dos días más tarde, el Ministro de Justicia y Negocios Eclesiásticos pidió al cabildo que abrieran las puertas de la Iglesia porque con esa medida se incitaba a la sedición. Finalmente, como ya lo esperaba el gobierno, estalló la protesta armada. Como dijera Justo Sierra:

La rebelión estalló en forma de una protesta armada contra la permanencia en el poder de Gómez Farías y contra la ley de enero y los legisladores; después de todo se concretó en un punto. Hubo luchas incesantes en la ciudad, muy poco sangrientas. Como en los batallones rebeldes preponderaban los jóvenes de la clase acomodada, a quienes se daba el nombre de polkos, así se llamó la facción, y con este nombre se contrapuso a los puros. $^{27}$

Las relaciones entre los ministros de Hacienda y Justicia y Negocios Eclesiásticos y los miembros del cabildo eran cada vez más tensas. Dichas relaciones se agravaron con la ley publicada el 4 de febrero,

${ }^{26}$ Acta del Cabildo de la catedral metropolitana del 12 de enero de 1847.

${ }^{27}$ Fragmento del texto de Justo Sierra, Evolución politica del pueblo mexicano, compilada por Josefina Vazquez de Knauth en Mexicanos y Norteamericanos ante la guerra del 47, 1972, México, SepSetentas n 19, p. 162. 
que facultaba al gobierno, de forma extraordinaria, a proporcionarse cinco millones de pesos. ${ }^{28}$ Más tarde, el gobernador del Distrito dio orden a los escribanos para que intervinieran las fincas urbanas de la Iglesia, notificando a los inquilinos que no pagaran la renta a las instituciones eclesiásticas sino al gobierno. ${ }^{29}$

Entretanto, el general Santa Anna enfrentaba al Ejército norteamericano en Saltillo sin haberes y con una soldadesca ignorante de los rudimentos de la guerra: a pesar del arrojo y la valentía de los mexicanos, la derrota era previsible antes de la batalla de la Angostura. En este contexto, el 23 de febrero el cabildo envió una representación al gobierno oponiéndose a las leyes del 19 de enero y del 4 de febrero relativas a la ocupación de los bienes eclesiásticos. ${ }^{30} \mathrm{El}$ escrito, sin ofender a autoridad alguna, expresaba el repudio más absoluto a las leyes mencionadas, a la ocupación de sus rentas y a las enajenaciones de los capitales y las fincas eclesiásticas que se habían iniciado.

Se protestaba con toda claridad y con toda justicia, sin que por ello se dejara de reconocer la soberanía absoluta de la República mexicana. Pero el gobierno debería recordar que la Iglesia de Jesucristo, que era una y la misma en todo el mundo, también era soberana e indepen60 diente. Destacaban que con esos decretos sólo se iba a beneficiar a los acreedores, quienes no desaprovecharían la oportunidad de especular con los bienes eclesiásticos y la triste situación del país. Si esto fuera así, decía el cabildo, ¿Cómo se acallarán las quejas del soldado que perece en la guerra y del ciudadano que llora la pérdida de los bienes eclesiásticos, cuando se acuse a la administración de haber tomado unos bienes sagrados para hacerlos pasar a las arcas del rico, del palaciego y del agiotista?" También señalaban los efectos sociales negativos que acarreaba la aplicación de los decretos mencionados:

${ }^{28}$ Acta del Cabildo del 6 de febrero de 1847.

${ }^{29}$ También empezó a circular el rumor de que el gobierno había ofrecido cinco mil pesos al sacristán de la catedral para que dijera en dónde se guardaba la plata de la Iglesia.

${ }^{30}$ Acta del Cabildo del 22 de febrero de 1847. 
EL CABILDO DE LA CATEDRAL

Cuando las fincas urbanas hayan pasado a la propiedad particular ¿quién podrá calcular el aumento de la miseria porque esa multitud que puede ocupar las casas por módicos arrendamientos, se verá lanzada de ellas por los subidísimos que les impondrán los nuevos dueños. La clase agrícola, la que merece en todos los países la mayor protección, y que en México se sostiene casi en su totalidad con los capitales de la Iglesia, al pequeño rédito de cinco por ciento anual ¿dónde hallará caudales para redimir aunque se le remita la mitad? Y en lo sucesivo ¿dónde encontrará capitales al 5\% anual? La multitud inmensa que se mantiene del cultivo de los campos ¿dónde hallará el sustento cuando las labores paren por falta de caudales? ¿Quién será capaz de medir el tamaño de las calamidades que la ruina de la agricultura traerá sobre los mexicanos?...Por lo que toca al orden público ¿Podrá alguno lisonjearse con la esperanza del orden y la paz, en una nación sumida en la mayor mendicidad, si en tiempo bonancibles, las necesidades y codicia de algunos la han tenido en constante trastorno? Es seguro señor que a la ruina de los particulares se seguirá la de la nación. ¿Qué espantoso es el pensar que entonces la República mexicana podrá ser sin dificultad presa de sus enemigos exteriores! Destrozada y sin recursos, el pueblo en la miseria, abandonados los campos, el patriotismo inextinguible de los mexicanos sólo serviría para sacrificarlos sin esperanza...¿Podrá un pueblo cristiano, un legislador católico, despreciar como ridículos estos temores?

La representación, que marcó la línea de las que se promulgarán de 1856 a 1876, afirmaba que las leyes no sólo habían sido repudiadas en algunos estados, sino que los gobernadores habian mandado que no se cumplieran en sus territorios. De ahí que la medida sólo se aplicaría en la ciudad de México. Y sólo de ella se tratarían de sacar los cinco millones que estipulaba la ley del 4 de febrero. Se aniquilaría la Iglesia y la misma capital con la medida. Es interesante que en la representación se reconoce la enorme necesidad de recursos que tiene el 


\section{MARTA GARCÍA UGARTE}

gobierno para sostener la guerra "que tan sin razón han provocado los americanos invasores”. En esa circunstancia, se decía, “quién osaría decir que la Iglesia se niega a auxiliar en la debida proporción para sostener la guerra hasta obtener el triunfo de la justa causa que México defiende?". No se podía acusar al clero de resistirse a contribuir para financiar la guerra. La Iglesia estaba dispuesta a colaborar, pero las leyes le habían arrebatado sus bienes sin su consentimiento. En suma, pedían al Congreso derogara los mencionados decretos. ${ }^{31}$

Mientras la oposición eclesiástica, apoyada por los hacendados, casi sumía al país en otra asonada interna, Santa Anna perdía en la Angostura y otro ejército estadounidense ocupaba Tampico. Ante la situación tan desesperada, Santa Anna pidió un préstamo a la Iglesia de 200 mil pesos para combatir a las tropas invasoras en el norte y a las de Winfield Scott en Veracruz.

Para entregar los primeros 10 mil pesos del nuevo préstamo, la Iglesia se veía obligada a vender alguna finca. Posteriormente, el presidente solicitó un préstamo de un millón y medio de pesos, comprometiéndose a abonar 125 mil pesos mensualmente durante un año. El cabildo consideraba que era imposible que la Iglesia pudiera entregar esa can-

62 tidad, cuando aportaba 20 mil pesos mensuales a cargo del préstamo anterior de $850 \mathrm{mil}$.

Este último préstamo era urgente porque el partido liberal estaba trabajando intensamente contra el gobierno y su caída era previsible si el clero no lo apoyaba. ${ }^{32} \mathrm{El}$ cabildo argumentaba que estaba dispuesto a apoyar con la mensualidad que se le estipulaba, los $125 \mathrm{mil}$ pesos mensuales, pero que careciendo de numerario era preciso vender muchas fincas. A pesar del sacrificio que representaba para la Iglesia, el cabildo aceptó otorgar las cantidades pedidas por el gobierno.

${ }^{31}$ Los obispos de Morelia, Oaxaca y Guadalajara se sumaron a la protesta realizada por el cabildo de México. Algunos, como el de Monterrey, estaba fuera de su diócesis desde que el Ejército norteamericano tomó la ciudad.

${ }^{32}$ Acta del Cabildo del 29 de marzo de 1847. 


\section{EL CABILDO DE LA CATEDRAL}

Al caer Veracruz, Santa Anna dejó el gobierno de la República al general Anaya, y emprendió el camino a Jalapa para impedir el avance de las tropas norteamericanas que comandaba el general Scott. Ante el avance de las tropas, el cabildo exhortó a todos los obispos para hacer ruegos solemnes y triduos fervorosos para pedir la paz. ${ }^{33}$ Además, el 9 de abril de 1847 se acordó, con el Ministro de Hacienda Juan Rondero, el préstamo de un millón y medio de pesos para sostener la guerra con Estados Unidos. Para pagarlo la Iglesia empezaría a enajenar algunas fincas, empezando por aquellas cuya venta fuera menos perjudicial. También se procedería a la fundición y venta de algunas piezas de plata, cuyo uso fuera menos necesario. ${ }^{34}$

$\mathrm{Ni}$ las plegarias ni el dinero entregado por la Iglesia impidieron el avance del general Scott a Puebla. Tanto el gobierno de la ciudad como los civiles que organizaban su defensa pidieron algunas campanas que pudieran fundirse para hacer cañones. El colector de Toluca y algunos otros, aportaron algunas cantidades a los que se aprestaban a la defensa de la capital. La sociedad de los amigos de la independencia pidió al cabildo que le donara las cadenas del cementerio para elaborar el armamento que requerían las guerrillas que se estaban organizando. Por su parte, el gobierno pidió apoyo para comprar un número considerable de fusiles cuyo precio ascendía a 375 mil pesos. Para no gravar más a la arquidiócesis, el gobierno proponía al cabildo que aceptara la mensualidad de 30 mil pesos que desde junio empezaría a entregar la diócesis de Michoacán por el crédito que había aceptado su obispo de 600 mil. El cabildo rechazó esta propuesta porque ignoraban los sacrificios que estaba haciendo el obispo de Michoacán para cubrir ese préstamo. ${ }^{35}$

En junio el gobierno volvió a solicitar a la Iglesia que se prestara a ofrecer hipoteca de sus bienes para garantizar un préstamo de $40 \mathrm{mi}-$ llones que se concertaría en Inglaterra, bajo la protección del gobierno

${ }^{33}$ Acta del Cabildo del 7 de abril de 1847.

${ }^{34}$ Acta del Cabildo del 15 de abril de 1847.

${ }^{35}$ Acta del Cabildo del 28 de mayo de 1847. 
de ese país. Como esta hipoteca consideraba los bienes eclesiásticos de toda la República, el cabildo respondió al gobierno que su aprobación correspondía a la Santa Sede. ${ }^{36}$ El Presidente se indignó porque el cabildo se negaba a entregar la hipoteca que solicitaba. De forma airada les dijo a los capitulares que tenía 20,000 hombres en armas a los que era preciso sostener y mantener, por lo que solicitaba un nuevo préstamo de millón y medio de pesos. ${ }^{37}$ Como el gobierno insistía en el préstamo, se acordó que se le prestaran $120 \mathrm{mil}$.

Las tropas nacionales abandonaron la ciudad el 13 de septiembre de 1847, y el general Scott ocupó el Palacio Nacional el día siguiente a las 10 de la mañana. ${ }^{38}$ El Vicario capitular, Juan Manuel Arzobispo de Cesarea, abandonó la ciudad antes de la llegada de los norteamericanos porque temía que lo persiguieran por el apoyo que había dado al gobiemo. Mientras el pueblo defendía la ciudad, que había sido abandonada a su suerte por el que fungía como titular de la sede arquidiocesana, el Ejército y el general Santa Anna, el cabildo dejó de celebrar reuniones: la presidencia de la República estaba desocupada y el destino de la nación era incierto. No obstante, como establecía la Constitución, el presidente de la Corte de Justicia, Manuel Peña y 64 Peña, asumió la presidencia y se trasladó con el gabinete y el congreso a la ciudad de Querétaro. De esa forma se estableció un gobierno constitucional que podía iniciar las negociaciones con el Ejército invasor.

\section{El Ejército invasor en la ciudad de México}

El general Winfield Scott nombró al general John A. Qitman gobernador civil y militar y ordenó que todos los militares se presentaran ante el gobierno estadounidense a fin de que firmaran un compromiso de no

${ }^{36}$ Acta del Cabildo catedralicio del 14 de junio de 1847.

${ }^{37}$ Actas del Cabildo del 9 y el 12 de julio de 1847.

${ }^{38}$ Ver el trabajo de María Gayón Córdova, "Los invasores yanquis en la ciudad de México" en Laura Herrera Serna, coordinadora, México en guerra (1846-1848), 1997, México, Conaculta. 
volver a utilizar las armas. Impuso una contribución de guerra de 150 mil pesos, y confirmó la administración municipal que estaba en funciones. El gobierno de Querétaro se opuso a las relaciones 'amistosas' del ayuntamiento de México con el enemigo, que ponían en entredicho su patriotismo.

A pesar de las declaraciones previas de que el Ejército norteamericano sería protector de los bienes de la Iglesia, el general no logró establecer una buena relación con los eclesiásticos tanto porque no entendía su dinámica como porque empezó a ocupar algunos conventos para instalar la tropa. Además, sus soldados habían cometido algunos atentados en los templos. ${ }^{39}$

Por su parte, el cabildo se comenzó a preocupar por encontrar la forma de seguir aportando las mensualidades comprometidas con el gobierno y con los particulares. Como se sabía que a pesar de las dificultades que tenía para pagar las mensualidades comprometidas, la Iglesia estaba financiando al gobierno nacional, el gobernador norteamericano de la ciudad prohibió la enajenación de las fincas eclesiásticas. El cabildo pidió al general Scott que derogara la prohibición. Pero este general contestó que la medida se había tomado precisamente porque temían que la Iglesia remitiese auxilios al gobierno mexicano. Deseando de cualquier modo cubrir su compromiso, la iglesia logró reunir 50 mil pesos por la fundición de algunas piezas de oro y plata, destinando 20 mil para el pago de las libranzas. ${ }^{40}$

Las buenas relaciones de la Iglesia con el Ejército invasor eran prácticamente imposibles no sólo por las diferencias religiosas sino por la frecuente falta de respeto al culto católico por parte de los soldados, contenidos con dificultad por el general Scott, como reconocían los capitulares. Dado que, obviamente, no se los podía obligar a que simularan adoraciones al paso del santísimo, éste era llevado a los enfermos de noche y con discreción. ${ }^{41}$

${ }^{39}$ El prior del convento de Santo Domingo decidió cerrar la Iglesia por los atentados de los americanos. Acta del cabildo del 17 de enero de 1848.

${ }^{40}$ Acta del 26 de noviembre de 1847.

${ }^{41}$ Acta del Cabildo del 30 de octubre de 1847. 


\section{MARTA GARCÍA UGARTE}

Aun cuando los habitantes de la ciudad tuvieron que acostumbrarse a vivir con los norteamericanos, y algunos incluso disfrutaron de su amistad y compañía, el gobierno nacional mexicano se había ganado el respeto social por mantener viva la nación.

\section{Epílogo}

Las negociaciones para el restablecimiento de la paz culminaron con la firma del Tratado Guadalupe Hidalgo del 2 de febrero de 1848. Bajo lo acordado México perdió las provincias de Alta California y Nuevo México, recibiendo a cambio la posibilidad de continuar como nación independiente y el pago de 15 millones de pesos (un monto insignificante; la misma cantidad que había solicitado el gobierno a la Iglesia en 1847).

El 12 de junio salieron las tropas norteamericanas de la capital de la República, y a medida que salían los sentimientos de desamparo y de inconformidad con la clase política y militar nacional se iban instalando en la sociedad mexicana. A la sombra de esos sentimientos, las viejas aspiraciones monárquicas resurgieron con fuerza insospechada. La Iglesia tampoco salió bien librada. Los convenios, conflictos y desavenencias con los gobiernos, la sensación prevaleciente de que no había sido lo suficientemente patriota, (no obstane los constantes montos mensuales aportados al gobierno), amén de la presencia de los norteamericanos en la ciudad que introdujeron el culto protestante, fueron factores combinados que minaron la catolicidad de la sociedad mexicana. Por otra parte, las relaciones armoniosas entre la Iglesia y el Estado, que habían sido impulsadas por los obispos nombrados por Gregorio XVI, se rompieron de forma absoluta al iniciarse la década de los cincuenta y el papado de Pío IX. Nada volvería a ser lo mismo. 